\title{
Life tests of a rotary single-stage magnetic-fluid seal for shipbuilding applications
}

\author{
Leszek Matuszewski, Ph.D. \\ Gdansk University of Technology \\ Zbigniew Szydło, Ph.D. \\ AGH University of Science and Technology
}

\begin{abstract}
Use of the magnetic fluid seal technology in water is much more difficult technological problem in comparison to gas or vacuum environment. Some seals constructed up to time been are designed as hybrid, two stage sealing structures with shields or mechanical seals used as protection measures to the magnetic fluid seal. Anyway, there is always problem with immediate contact between magnetic fluid and the environmental liquid. In the paper are presented results of experiments carried out with one stage rotating magnetic fluid seal operating in immediate contact with utility water. The special test procedures have been elaborated and practically used, with the aim to define main characteristics of magnetic fluid seals and to simplify experiments. These characteristics were: critical pressure, critical motion velocity and working life of the seal. Four grades of commercial, silicon based magnetic fluids of hydrophobic properties were tested in a single stage sealing system. The results of tests are presented in the form of tables and diagrams. It is concluded that hydrophobic commercial magnetic fluids could be efficiently used in rotating shaft seals however in a limited range of motion velocity.
\end{abstract}

Keywords: shaft sealing; magnetic fluid; utility water; seal durability; critical pressure; critical motion velocity

\section{INTRODUCTION}

The sealing technique of shafts, covers, pipe penetrations and many other mechanical units with the use of ferro-fluids has been successfully applied to machinery operating in rotational or reciprocating motion. Many experimental and theoretical investigations have been devoted to problems of design, choice of materials and ferro-fluids for seals intended for operating in gas environment or vacuum, owing to which very effective and simple solutions of sealing problems in many technical devices, have been obtained [1].

Theoretical elaboration and design solution of ferro-fluid seals intended for operating in sea water and other liquids is much more difficult than in the case of gas environment or vacuum. Sealing a liquid requires many additional factors which appears in direct interphase contact of two environments being in the same physical state, e.g. a ferro-fluid and sealed liquid, to be taken into account. An essential condition for correct operation of a seal in such circumstances is complete lack of susceptibility to mixing together sealing fluid and sealed one. It means that in the seal in question a ferro-fluid of properties ensuring high interphase surface tension on the phase separation surface between sealing (magnetic) fluid and sealed (non-magnetic) one, should be used.

In static conditions, when seal's elements do not mutually displace, fulfillment of the conditions, at correct design of the unit, ensures a sufficient life of seals of the kind; hence they may be successfully used in shipbuilding. Lack of susceptibility to mixing and high interphase surface tension may appear not sufficient factors if a magnetic-fluid (MF) seal is applied in its motion conditions or in case of sealed liquid flow, e. g. around ship propeller shaft. Relative displacement of two non-mixing together liquids results in generating surface instability at the interphase boundary [2, 3], whose intensity fast increases over a limiting difference of velocity, that causes magneticfluid sweeping and loss of system sealing. Research work on operation of MF seals in liquid environment has been conducted by some research centres, however only a few relevant reports are available. In the publications $[4,5,6]$ was described research on possible operation of MF seals in sea water depending on pressure and shaft peripheral speed. Anyway these studies were mainly focused on defined technological goals without more general considerations.

In [7] was described a hybrid sealing system for liquid pump, where MF seal is introduced as the second sealing stage (two - stage system), placed in series behind a mechanical one. However the author did not attach any operational test results of the solution.

One of the particular examples of MF seal applications in interaction with liquid is the seal of precise rotor of a pump used in medicine for blood pumping during operations. The pump including the seal was elaborated by a team under supervision of Mitamura, Y. [8].

The authors of the elaboration carried out experimental work on MF seals operating in utility water environment. The research was conducted on a special test stand adjusted to MF 
seal operation in liquids [9]. In view of utilitarian character of the research, MF multi-stage seals being models of real ferro-fluid seals were used, and their operational conditions were limited according to the assigned task. Despite the simplifications, the obtained results demonstrated that it is possible to apply some commercial magnetic fluids to MF seals working in direct contact with water in operational conditions occurring on ships and many other marine technical objects $[10,11,12]$

Loss of tightness of MF seal operating in water results from complex physical processes and depends also on many geometrical and motional factors. Diagnosis of the processes and assessment of possible operation of MF seals in water require to perform a wide range research with the use of various magnetic fluids of hydrophobic properties in seals of different geometry and in various operational conditions. And, basic tests should be performed with the use of a single-stage seal.

MF single-stage seals are very seldom used in sealing systems of rotary shafts of propellers or similar technical devices. In practice multi-stage seals are used and number of their stages is usually even [1] that results from magnetic circuit physical features. However investigation of a single sealing stage is a very essential experimental task as it can make it possible to recognize phenomena which occur in the seal, in a more transparent way than in the case of a multi-stage seal. This concerns especially MF seals operating in water (or other liquids) as in such systems to determine the instant of loss of tightness is more difficult than in the case of testing the seals in gas environment or vacuum. Investigations of MF single-stage seal operating in gas environment are presented in the publication [13] devoted mainly to problems of pressure to puncture and torque of seal resistance to motion. In the investigations the test stand called shortly MASTL1 - V2 was used. The stand is composed of a test head especially adjusted for performing assigned research tasks, driving system consisted of an electric motor and its controller, as well as a measuring system consisted of sensors and transducers for measuring values of pressure, motor torque and operational temperature. The stand is equipped with a multi-channel measuring system for acquiring, processing and recording measurement data.
Four kinds of magnetic fluids of hydrophobic properties were tested. These are magnetic fluids produced by FERROLABS Inc., a Russian firm, located in Sterling, VA, USA [17]. The investigations were conducted in the conditions of equal magnetic field (equal number of magnets and their arrangement in seal magnetic system).

\section{TEST STAND}

The MAST L1-V2 test stand is that used for testing magnetic fluid seals operating in contact with water or other liquids, located in the Laboratory of Seals and Application of Magnetic Fluids, AGH University of Science and Technology in Krakow. Dimensions of the head make it possible to place within it a magnetic fluid seal of $50 \mathrm{~mm}$ diameter equivalent to that of propeller shafts of fish cutters and smaller boats. In future tests to increase the diameter to at least $200 \mathrm{~mm}$ corresponding to that of shafts of medium ships is recommended. It should be checked whether and to which extent scale effect may occur. Only a small amount of magnetic fluid, namely about $50-200 \mu 1$, is necessary to fill gaps of the stages sealing the $50 \mathrm{~mm}$ shaft.

The MAST L1-V2 test stand makes it possible to determine static puncture pressure of seal, limiting operational speed of seal, and its life for a given rotational speed up to $120 \mathrm{~s}^{-1}$ and pressure up to $0.1 \mathrm{MPa}$.

\section{Design of the test head used in MAST L1-V2 test stand}

In Fig. 1 is presented the head of the MAST L1-V2 test stand for research on magnetic - fluid seals operating in liquid environment. In the testing part of the head is placed the testing sleeve of sealing stages, 1, located on the hollow rotary shaft 18 seated in the slide bearings 19 mounted at the motionless casing 20. On the casing 20 the test head pivoting body 6 is seated in the slide bearings 21 . In the body 6 is placed: the set of permanent magnets, 3 , with pole shoes 2 , and the sleeve 1 , which form, together with magnetic fluid, a closed magnetic circuit. In the body 6 is fixed the casing of the sealed fluid chamber 5 closed with the transparent plate 7 .

\section{Partial section with the seal details shown in Fig. 2}

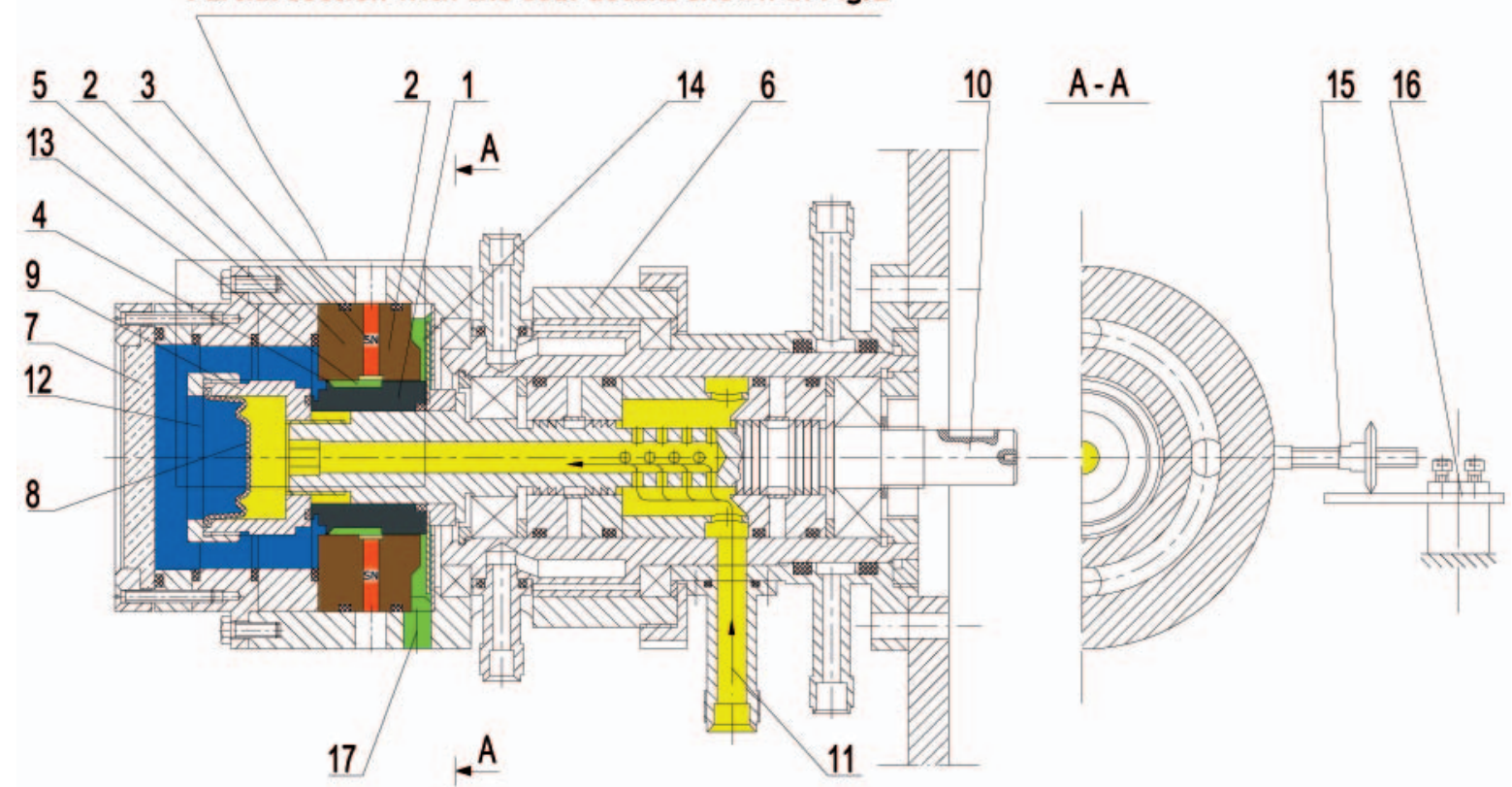

Fig. 1. The structure of MAST L1-V2 head intended for testing magnetic fluid seal operating in liquid environment: 1 - sigle-stage sleeve, 2 - pole shoes, 3 - permanent magnets, 4 - magnetic fluid, $\mathbf{5}$-test chamber casing, $\mathbf{6}$ - test head pivoting body, 7 - test chamber transparent cover, $\boldsymbol{8}$ - rubber membrane, 9 - rubber membrane holder, 10 - rotary shaft, 11 - compressed air passage, 12 - set pressure zone of fluid-filled chamber, 13 - fluid penetration zone, 14 - fluid outflow zone after leakage from tested seal, 15 - thrust arm of torque meter, 16 - extensometric beam, 17 - leakage draining hole 


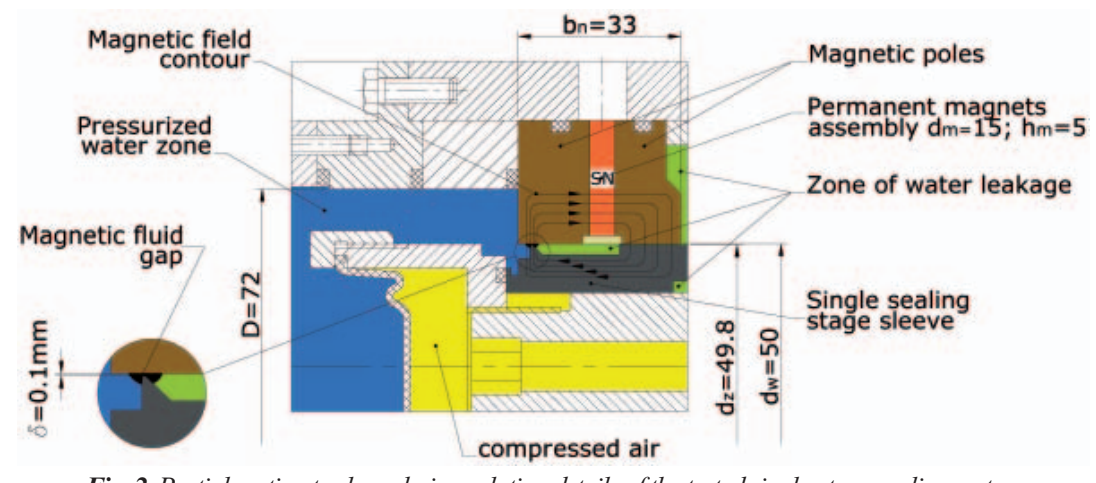

Fig. 2. Partial section to show design solution details of the tested single-stage sealing system

Inside the chamber 5, is placed the rubber membrane holder 9 , mounted on the threaded end of the shaft 10 . In the holder 9 , is fixed the membrane 8 , which separates the chamber zone filled with the sealed fluid, 12, from the zone of the compressed air supplied through the passage 11 and the hole in the shaft 10. The compressed air is delivered to the elastic membrane to rise pressure in the sealed fluid. Balance obtained between fluidal medium pressure and gaseous medium pressure means that the seal prevents the fluid from leaking. If the magnetic fluid seal loses its tightness the sealed fluid penetrates to the zone 13, next finds its way to the fluid outflow zone 14, and further, through the leakage draining hole 17 , flows out to the leakage tank (Fig. 4, item 8). The sealed fluid loss in the zone12, makes the compressed gas pressure dropping, which is recorded by the pressure sensor. The pressure indications will serve as auxiliary diagnostic signals if direct observation of dropping leakage is not possible.

In Fig. 2 the design solution details of the tested single-stage sealing system, are presented. There are demonstrated: path of magnetic field lines, location of the zones of compressed air and water, as well as leakage zone and details of the seal with indicated location of the magnetic fluid and height of the gaps tested in the seal.

\section{Drive and control \&measurement systems of the MAST L1-V2 test stand}

In Fig. 3 the schematic diagram of the drive and control \& measurement systems of the MAST L1-V1 test stand, are presented. The electric motor 1 drives the test head shaft 3 through the elastic coupling 2. Basically, the test stand's casing is composed of two parts: the motionless part fixed in the base 7 through a special fixing device, and the moving part set through bearing system in the motionless part where the pole shoes and the permanent magnets are placed. During testing the seal, air is under pressure delivered from the tank 17 , by using the air compressor 16 , to the inlet stub pipe 10. Pressure of the air delivered to the inlet stub pipe 10 is measured by using the Danfoss MBS 32 pressure sensor, 21, of the measuring range from 0 to $1 \mathrm{MPa}$, as well as by means of an indication manometer of the measuring range from 0 to 0.1 MPa. Rotational speed of the driving motor 1 is controlled by means of the frequency converter PCZ which makes it possible to measure driving shaft rotational speed and power absorbed by the motor.

Signals of pressure, temperature, torque, rotational speed and absorbed power are sent through the measurement channels $24,25,26,27$ and 28 to the control \& supply panel PSZ, and next to the NI USB-6009 eight-channel measurement card KP (of National Instruments), which cooperates with the computer PC by making use of the LabVIEW 8.5 software, also of National Instruments origin.

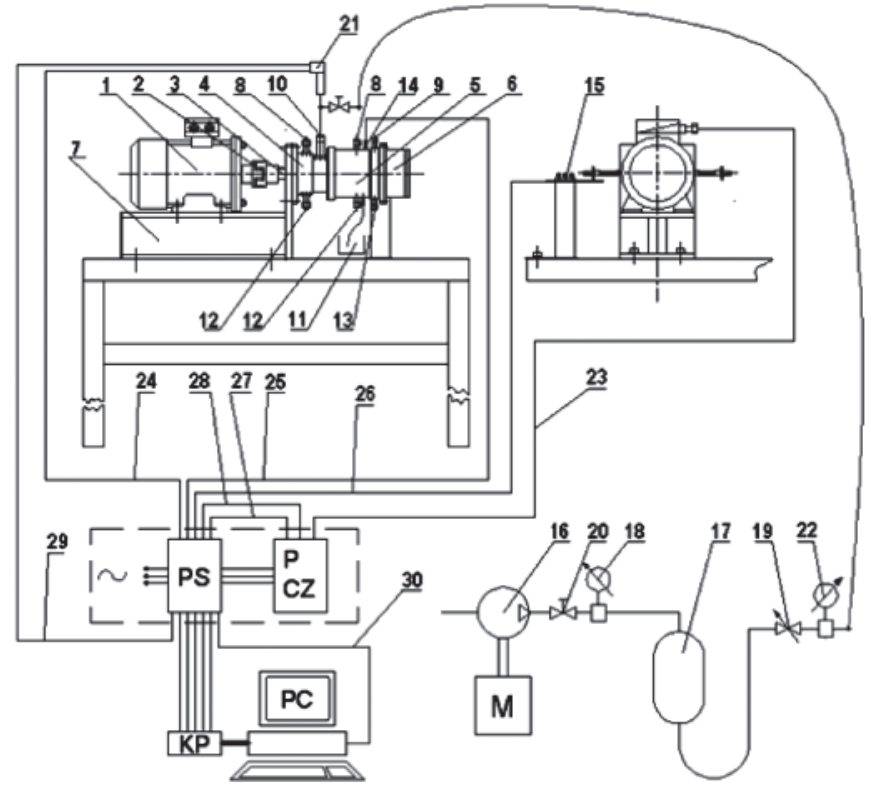

Fig. 3. Schematic diagram of the drive and control \&measurement systems of the MAST L1-V1 test stand intended for the testing of magnetic-fluid seals: $\mathbf{1}$-electric motor; $\mathbf{2}$ - coupling; $\mathbf{3}$-rotary shaft; $\mathbf{4}$-casing of shaft bearing; 5 - pivoting casing of head's bearings; $\mathbf{6}$ - test chamber's casing, 7 - base; $\boldsymbol{8}$-inlet stub pipes of cooling system of shaft sealing; $\mathbf{9}$-inlet stub pipe of tested seal cooling; 10 - stub pipe of compressed air delivery system; 11 - leakage tank; 12 - outlet stub pipes of cooling system of shaft sealing; 13 - outlet stub pipe of tested seal cooling; 14 -temperature sensor; 15 - extensometric beam for torque measuring;

16 - air compressor; 17 - compressed air tank; 18 - pressure reducing

valve; 19 -driving motor supply control valve; 20 - cut-off valve;

21 - pressure measuring transducer; 22 - manometer; 23 -driving motor supply; 24, 25, 26, 27, 28-measurement channels of: pressure, temperature, torque, rotational speed and power, respectively;

29, 30 - supply of pressure transducer and computer measurement system, $\boldsymbol{P S}$ - control \& supply panel; $\boldsymbol{P C Z}$ - frequency converter,

$\boldsymbol{K P}$ - measurement card; $\boldsymbol{P C}-P C$ computer; $\boldsymbol{M}$ - air compressor motor

In Fig. 4 is presented a photo of the MAST L1 test stand together with the control \& supply panel and computer measurement system intended for aiding and recording run of the testing.

\section{CONCEPT AND SCOPE OF THE TESTS}

Many factors affect a seal material and technological characteristics when water and particularly sea water is operating environment. These are: environmental pressure, motion velocity of the seal combined with the flow intensity and velocity of water, temperature and chemical reactivity of water against the magnetic fluid and other components of the seal. Some of the factors e.g. environmental pressure and the mixing ability of water and magnetic fluid may result in instantaneous leakage when others like motion velocity of the 


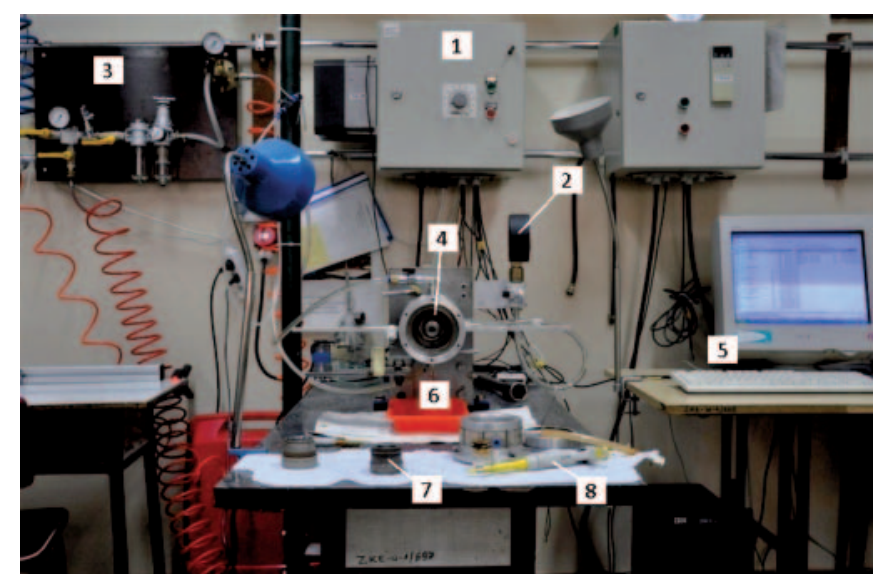

Fig. 4. MAST L1 stand shown with open chamber for preparation a test run. control \& supply panel and of the testing: 1 -control \& supply panel, 2 - manometer to measure pressure in test chamber, 3 -compressed air preparation supply system, 4 - test head open to show magnetic poles, 5 - computer aided measurement and record system, $\mathbf{6}$ - leakage tank,

7 - single stage seal sleeve, $\boldsymbol{8}$ - precise magnetic fluid metering device

seal, temperature and chemical activity are hazardous in view of long life effectiveness of the seal.

In tests were used magnetic fluids with high mixing resistance to water, and test pressures were selected far below critical pressure of the seal to avoid the risk of instantaneous break of the seal.

Owing to long time tests necessary to define time durability of the seal it was decided to carry the single factor tests based on the assumption that the motion velocity is the factor deciding on the seal durability in water environment with outer pressure maintained below the critical pressure and temperature within $20^{\circ} \mathrm{C}-25^{\circ} \mathrm{C}$. This assumption has been supported by results of earlier research [12].

The research concept has been based on the preliminary assumption that the factor decisive of life of seal which operates in water environment is speed of its motion.

To realize the research concept a scope of work comprising both short-term and long-term tests, was elaborated. The shortterm tests were aimed at determining critical conditions for seal operation, i.e. seal critical pressure and critical speed of its motion. The long-term tests were focused on determining life of the seal depending on its motion speed.

The critical pressure was measured during the static test (motionless seal) at water pressure continuously increasing in the test chamber till occurrence of water leakage.

Pressure value at which the leakage takes place has been assumed critical. The pressure was used to determine values of water pressure to be set in the test chamber both during critical motion measurements and long-term life tests of the seal. In the research use was made of the notion of the relative pressure $\mathbf{p} / \mathbf{p}_{\mathbf{k r}}$, i.e. the ratio of the set pressure and the critical pressure, characteristic for a given type of tested seal.

The seal motion critical speed was measured at the relative water pressure $\mathbf{p} / \mathbf{p}_{\mathbf{k r}}=\mathbf{0 . 5}$ set in the test chamber. The measurement consisted in continuous increasing seal rotational speed till occurrence of water leakage. The equal rate of rotational speed increasing (rotational acceleration) amounted to $1 \mathrm{~s}^{-2}$ (the rotational speed increasing from 0 to $120 \mathrm{~s}^{-1}$ within the time of $120 \mathrm{~s}$ ) was applied. Speed value at which leakage occurs was taken as the seal motion critical speed. The measurement of the critical pressure and seal motion speed was used for preliminary comparative assessment of the applied magnetic fluids.

Life of the seal in function of its motion speed was measured during the long-term test consisting in the seal operation under constant rotational speed and stationary pressure conditions in the test chamber (the relative pressure $\mathbf{p} / \mathbf{p}_{\mathbf{k r}}=\mathbf{0 . 5}$ ) and seal temperature, continued up to occurrence of water leakage. Total number of seal's rotations up to leakage was assumed equivalent to the seal's life in the set working conditions.

Although occurrence of leakage was taken as the main criterion for correct operation of seal, during the tests also friction torque, seal temperature and pressure, and shaft rotational speed was measured. The quantities served to control the tests running.

The tests in question were conducted according to the following programme:

- The static critical pressure test of the seal.

- The critical operational speed test of the seal at the relative pressure $\mathbf{p} / \mathbf{p}_{\mathrm{kr}}=\mathbf{0 . 5}$.

The life test of the seal at the relative pressure $\mathbf{p} / \mathbf{p}_{\mathbf{k r}}=\mathbf{0 . 5}$ under various motion speed values beginning from the maximum seal motion speed close to critical one up to the minimum speed under which the seal's life was equal at least to $1 \mathrm{mln}$ cycles.

The tests were performed with the use of four kinds of magnetic fluid applied to the single-stage seal with the magnetic-fluid-filled gap height $\delta=0.1 \mathrm{~mm}$.

\section{MATERIALS USED IN THE TESTS}

\section{Magnetic fluids}

In the tests four kinds of magnetic fluids produced by Ferrolabs Inc. [14] were used.

In Tab. 1 are presented characteristics of the delivered magnetic fluids, based on the data available from their producer.

Tab.1. Specification of the magnetic fluids used in the tests

\begin{tabular}{|c|c|c|c|c|c|c|c|c|}
\hline No. & $\begin{array}{l}\text { Magnetic } \\
\text { fluid }\end{array}$ & $\begin{array}{l}\text { Bearing } \\
\text { liquid }\end{array}$ & $\begin{array}{l}\text { Magnetic } \\
\text { particles }\end{array}$ & $\begin{array}{c}\text { Magnetization } \\
\text { of saturation, } M_{\mathrm{s}} \\
{[\mathrm{kA} / \mathrm{m}]}\end{array}$ & $\begin{array}{c}\text { Plastic viscosity } \\
\text { in } 20^{\circ} \mathrm{C}, \eta_{\mathrm{pl}} \\
{[\mathrm{Pa} \cdot \mathrm{s}]}\end{array}$ & \begin{tabular}{|c} 
Freezing \\
point \\
{$\left[{ }^{\circ} \mathbf{C}\right]$} \\
\end{tabular} & $\begin{array}{c}\text { Critical } \\
\text { temperature } \\
{\left[{ }^{\circ} \mathbf{C}\right]} \\
\end{array}$ & $\begin{array}{c}\text { Operational } \\
\text { temperature } \\
{\left[{ }^{\circ} \mathbf{C}\right]} \\
\end{array}$ \\
\hline 1 & FLS 040.040 & Silicon liquid & $\begin{array}{c}\text { Magnetite } \\
\mathrm{Fe}_{3} \mathrm{O}_{4}\end{array}$ & 45.00 & 0.550 & -100 & +200 & $-70 \ldots+150$ \\
\hline 2 & FLS 250.020 & Silicon liquid & $\begin{array}{c}\text { Magnetite } \\
\mathrm{Fe}_{3} \mathrm{O}_{4}\end{array}$ & 25.00 & 1.120 & -90 & +200 & $-60 \ldots+100$ \\
\hline 3 & FLA 003.45 & Siloxane & $\begin{array}{c}\text { Magnetite } \\
\mathrm{Fe}_{3} \mathrm{O}_{4}\end{array}$ & 45.00 & 0.450 & - & +200 & $-70 \ldots+150$ \\
\hline 4 & FLA 002.25 & Siloxane & $\begin{array}{c}\text { Magnetite } \\
\mathrm{Fe}_{3} \mathrm{O}_{4}\end{array}$ & 25.00 & 0.725 & - & +250 & $-70 \ldots+150$ \\
\hline
\end{tabular}


Tab. 2. Results of the tests with the use of FLS 040.040 magnetic fluid

\begin{tabular}{|c|c|c|c|c|c|c|c|c|}
\hline $\begin{array}{c}\text { Fluid } \\
\text { amount } \\
{[\mu \mathrm{l}]}\end{array}$ & $\begin{array}{l}\text { Gap } \\
\text { height } \\
{[\mathrm{mm}]}\end{array}$ & $\begin{array}{c}\text { Critical } \\
\text { pressure } \mathbf{p}_{\mathrm{kr}} \\
{[\mathrm{MPa}]}\end{array}$ & $\begin{array}{c}\text { Relative } \\
\text { pressure } \\
\text { p/ } / \mathbf{p}_{\mathrm{kr}}\end{array}$ & $\begin{array}{l}\text { Set testing } \\
\text { pressure } \\
\text { P [MPa] }\end{array}$ & $\begin{array}{c}\text { Critical } \\
\text { speed } \\
{\left[\mathbf{s}^{-1}\right]}\end{array}$ & $\begin{array}{c}\text { Testing } \\
\text { rotational speed } \\
{\left[\mathrm{s}^{-1}\right]}\end{array}$ & $\begin{array}{l}\text { Number of } \\
\text { revolutions } \\
\text { to leakage }\end{array}$ & $\begin{array}{l}\text { Time to } \\
\text { leakage } \\
{[\text { [s] }}\end{array}$ \\
\hline \multirow{4}{*}{100} & \multirow{4}{*}{0.1} & \multirow{4}{*}{0.0776} & \multirow{4}{*}{0.5} & \multirow{4}{*}{0.039} & \multirow{4}{*}{73} & 73 & 730 & 20 \\
\hline & & & & & & 60 & 30000 & 500 \\
\hline & & & & & & 40 & 200000 & 5000 \\
\hline & & & & & & 20 & 9800000 & 49000 \\
\hline
\end{tabular}

The magnetic fluids used in the tests were produced on the basis of different kinds of silicon fluids of strong hydrophobic properties, that is the necessary condition for effective operation of MF seal in water. The fluids marked FLS 250.020 and FLS 040.040 are standard ones intended for the applying to seals, and the fluids marked FLA 002.25 and FLA 003.45 are those for using in acoustic devices, mainly loudspeakers.

The fluids for acoustic devices are characteristic of good heat abstraction, and satisfactory results as to their range of tightness keeping, obtained from their tests in seals.

In selecting the fluids also their saturation magnetization and viscosity values were taken into account. The two fluids of lower saturation magnetization but higher viscosity (FLS 250.020 and FLA 002.25) and the two fluids of higher saturation magnetization but lower viscosity (FLS 040.040 and FLA 003.45) were selected. This way it was possible to preliminarily assess impact of the parameters on sealing effectiveness in conditions of operation in water.

\section{Permanent magnets}

Magnetic field in the seal was generated by means of the set of permanent disk magnets circumferentially placed between the pole shoes of the seal's magnetic system. The commercial Neodymium 38 high-energy permanent magnets of the coercivity $\mathrm{H}_{\mathrm{c}}=912 \mathrm{kA} / \mathrm{m}$ and the magnetic energy density $(\mathrm{BH})_{\max }=294 \mathrm{~kJ} / \mathrm{m}^{3}[15]$ were used. The magnetic system was consisted of 14 disks of $\Phi 15 \times 5 \mathrm{~mm}$ in size, circumferentially evenly distributed in the space between the pole shoes.

\section{Pole shoes and sleeves of single sealing stage (lip)}

The pole shoes and single stage sealing sleeves were made of a low-carbon steel of the relative magnetic permeability $\mu_{\mathrm{r}}>2000$.

\section{CHARACTERISTICS OF THE TESTED SEALS}

The crucial geometrical and operational data of the tested seal are specified below.

Geometrical data (Fig.2):

- internal diameter of pole shoes (nominal diameter of seal): $\mathrm{d}_{\mathrm{w}}=50 \mathrm{~mm}$

- internal diameter of test chamber: $\mathrm{D}=85 \mathrm{~mm}$

- external diameter of sealing stage sleeve: $d_{z}=49.8 \mathrm{~mm}$

- gap height: $\delta=0.1 \mathrm{~mm}$

- number of sealing stages: $\mathrm{z}=1$

- breadth of the magnetic unit (pole shoes + permanent magnets): $b_{n}=33 \mathrm{~mm}$

- permanent magnet diameter: $\mathrm{d}_{\mathrm{m}}=15 \mathrm{~mm}$

- permanent magnet thickness: $\mathrm{h}_{\mathrm{m}}^{\mathrm{m}}=5 \mathrm{~mm}$

- number of permanent magnets: $\mathrm{L}=14$

\section{Operational data:}

- magnetic fluid amount delivered to the gap: $100 \mu \mathrm{l}$

- working medium pressure: $\mathrm{p}=(0.02 \div 0.1) \mathrm{MPa}$

- rotational speed range: $\mathrm{n}=(0-120) \mathrm{s}^{-1}$

- working medium: utility water

\section{RESULTS OF THE TESTS}

Results of the tests are given in the form of the tables containing both values of test parameters and results obtained from the tests, as well as in the form of the diagrams where values resulting from the tests are presented in function of the parameters of the tested seals or test duration time.

Results of the tests are given for each of the tested magnetic fluid, separately. In every test was applied the same sealing gap of $0.1 \mathrm{~mm}$ in height, to which $100 \mu \mathrm{l}$ of magnetic fluid was delivered. In the diagrams are also given trend- line equations of the best conformity with the obtained results.

\section{Results of the tests with the use of FLS 040.040 magnetic fluid}

In Tab. 2 are collected results of the tests with the use of FLS 040.040 magnetic fluid. The tests were performed at the relative pressure $\mathbf{p} / \mathbf{p}_{\mathbf{k r}}=\mathbf{0 . 5}$, consequently the pressure of $0.039 \mathrm{MPa}$ was set in the water chamber.

In Fig. 5 are presented the diagrams of number of seal revolutions to the first leakage in function of seal rotational speed for the FLS 040.040 magnetic fluid. The first measurement point depicted in the diagram concerns the test performed at the seal critical speed equal to $73\left[\mathrm{~s}^{-1}\right]$.

The trend-line equation is of the form:

$$
y=-7.14 \ln (x)+124.83
$$

\section{Results of the tests with the use of FLS 250.020 magnetic fluid}

In Tab. 3 are collected results of the tests with the use of FLS 250.020 magnetic fluid. The tests were performed at the relative pressure $\mathbf{p} / \mathbf{p}_{\mathbf{k r}}=\mathbf{0 . 5}$, consequently the pressure of $0.031 \mathrm{MPa}$ was set in the water chamber.

In Fig. 6 is presented the relation between number of seal revolutions (cycles) to the first leakage and seal rotational speed for the FLS 250.020 magnetic fluid. The first measurement point depicted in the diagram concerns the test performed at the seal critical speed equal to $22\left[\mathrm{~s}^{-1}\right]$.

The trend-line equation is of the form:

$$
\mathrm{y}=-1.54 \ln (\mathrm{x})+31.08
$$

\section{Results of the tests with the use of FLA 003.45 magnetic fluid}

In Tab. 4 are collected results of the tests with the use of FLA 003.45 magnetic fluid. The tests were performed at the relative pressure $\mathbf{p} / \mathbf{p}_{\mathbf{k r}}=\mathbf{0 . 5}$, consequently the pressure of $0.043 \mathrm{MPa}$ was set in the water chamber. 
Number of revolutions to leakage vs. motion velocity of the seal

Magnetic fluid: FLS 040.040

$\delta=0.1 \mathrm{~mm} ; \mathrm{p}=0.039 \mathrm{MPa} ; \mathrm{p}_{\mathrm{cr}}=0.078 \mathrm{MPa} ; \mathrm{p} / \mathrm{p}_{\mathrm{cr}}=0.5$

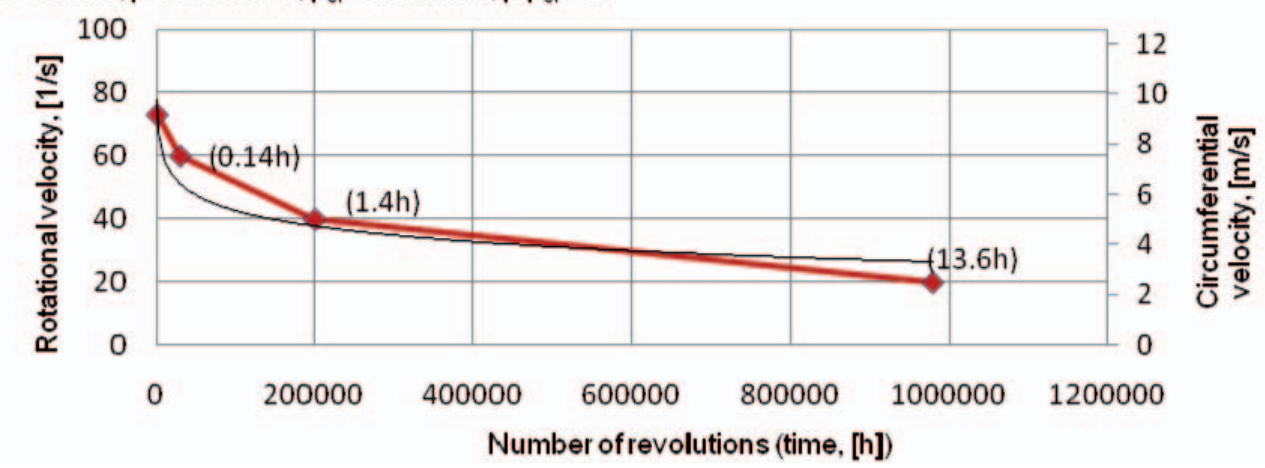

Fig. 5. Life of the seal with the applied FLS 040.040 magnetic fluid for the gap height of $0.1 \mathrm{~mm}$ and the set pressure of $0.039 \mathrm{MPa}$

Tab. 3. Results of the tests with the use of FLS 250.020 magnetic fluid

\begin{tabular}{|c|c|c|c|c|c|c|c|c|}
\hline $\begin{array}{c}\text { Fluid } \\
\text { amount } \\
{[\mu l]}\end{array}$ & $\begin{array}{l}\text { Gap } \\
\text { height } \\
\text { [mm] }\end{array}$ & $\begin{array}{c}\text { Critical } \\
\text { pressure } \\
{[\mathrm{MPa}]}\end{array}$ & $\begin{array}{c}\text { Relative } \\
\text { pressure } \\
\text { p/p }\end{array}$ & $\begin{array}{c}\text { Set } \\
\text { testing } \\
\text { pressure } \\
\text { P [MPa] }\end{array}$ & $\begin{array}{c}\text { Critical } \\
\text { speed } \\
{\left[\mathbf{s}^{-1}\right]}\end{array}$ & $\begin{array}{c}\text { Testing } \\
\text { rotational speed } \\
{\left[\mathrm{s}^{-1}\right]}\end{array}$ & $\begin{array}{l}\text { Number of } \\
\text { revolutions } \\
\text { to leakage }\end{array}$ & $\begin{array}{l}\text { Time to } \\
\text { leakage } \\
\text { [s] }\end{array}$ \\
\hline \multirow{6}{*}{100} & \multirow{6}{*}{0.1} & \multirow{6}{*}{0.0616} & \multirow{6}{*}{0.5} & \multirow{6}{*}{0.031} & \multirow{6}{*}{22} & 22 & 250 & 12 \\
\hline & & & & & & 20 & 500 & 25 \\
\hline & & & & & & 19 & 20900 & 1100 \\
\hline & & & & & & 18 & 32400 & 1800 \\
\hline & & & & & & 10 & 530000 & 53000 \\
\hline & & & & & & 7 & 980000 & 140000 \\
\hline
\end{tabular}

Number of revolutions to leakage vs. motion velocity of the seal

$y=-1.54 \ln (x)+31.08$

Magnetic fluid: FLS250.020;

$\hat{0}=0.1 \mathrm{~mm} ; \mathrm{p}=0.031 \mathrm{MPa}, \mathrm{p}_{\mathrm{cr}}=0.062 \mathrm{MPa} ; \mathrm{p} / \mathrm{p}_{\mathrm{rr}}=0.5$

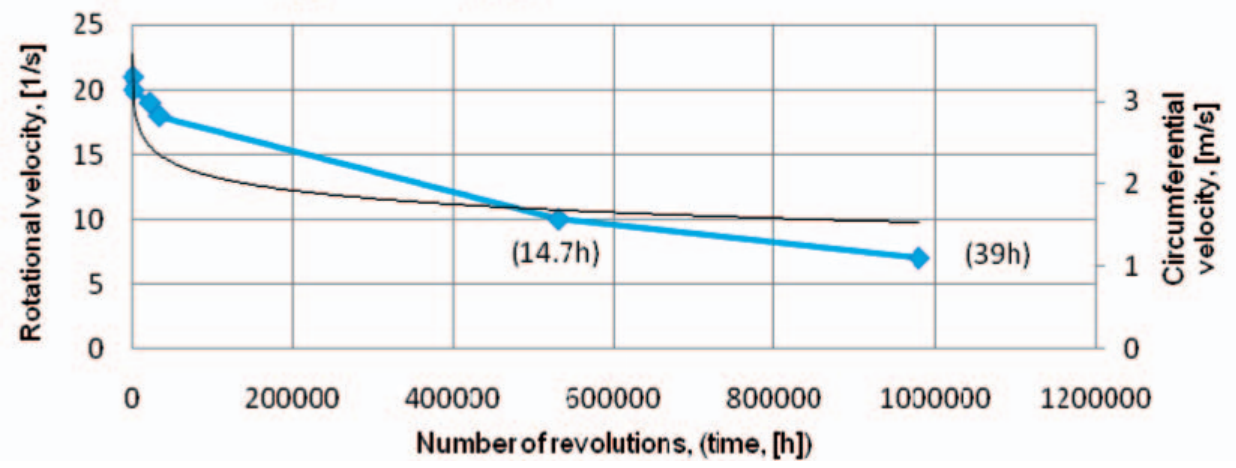

Fig. 6. Life of the seal with the applied FLS 250.020 magnetic fluid for the gap height of $0.1 \mathrm{~mm}$ and the set pressure of $0.031 \mathrm{MPa}$

Tab. 4. Results of the tests with the use of FLA 003.45 magnetic fluid

\begin{tabular}{|c|c|c|c|c|c|c|c|c|}
\hline $\begin{array}{c}\text { Fluid } \\
\text { amount } \\
{[\mu l]}\end{array}$ & $\begin{array}{c}\text { Gap } \\
\text { height } \\
{[\mathrm{mm}]}\end{array}$ & $\begin{array}{c}\text { Critical } \\
\text { pressure } p_{\mathrm{kr}} \\
{[\mathrm{MPa}]}\end{array}$ & $\begin{array}{c}\text { Relative } \\
\text { pressure } \\
\mathbf{p}^{\prime} \mathbf{p}_{\mathrm{kr}}\end{array}$ & $\begin{array}{c}\text { Set } \\
\text { testing } \\
\text { pressure } \\
\mathbf{P}[\mathrm{MPa}]\end{array}$ & $\begin{array}{c}\text { Critical } \\
\text { speed } \\
{\left[\mathbf{s}^{-1}\right]}\end{array}$ & $\begin{array}{c}\text { Testing } \\
\text { rotational speed } \\
{\left[\mathrm{s}^{-1}\right]}\end{array}$ & $\begin{array}{c}\text { Number of } \\
\text { revolutions } \\
\text { to leakage }\end{array}$ & $\begin{array}{c}\text { Time to } \\
\text { leakage } \\
\text { [s] }\end{array}$ \\
\hline \multirow{6}{*}{100} & \multirow{6}{*}{0.1} & \multirow{6}{*}{0.0868} & \multirow{6}{*}{0.5} & \multirow{6}{*}{0.043} & \multirow{6}{*}{82} & 82 & 850 & 22 \\
\hline & & & & & & 75 & 1375 & 28 \\
\hline & & & & & & 60 & 31200 & 520 \\
\hline & & & & & & 50 & 32000 & 640 \\
\hline & & & & & & 40 & 82000 & 2050 \\
\hline & & & & & & 30 & 1800000 & 60000 \\
\hline
\end{tabular}



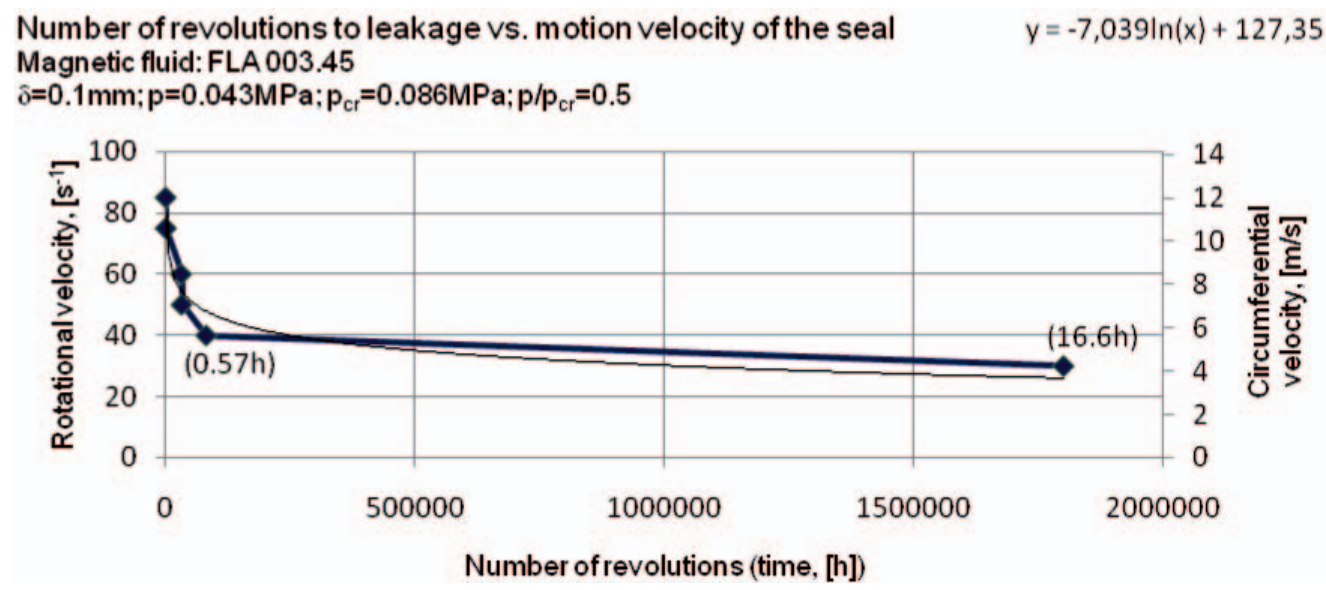

Fig. 7. Life of the seal with the applied FLA 003.45 magnetic fluid for the gap height of $0.1 \mathrm{~mm}$ and the set pressure of $0.043 \mathrm{MPa}$

In Fig. 7 is presented the relation between number of seal revolutions (cycles) to the first leakage and seal rotational speed for the FLA 003.45 magnetic fluid. The first measurement point depicted in the diagram concerns the test performed at the seal critical speed equal to $82\left[\mathrm{~s}^{-1}\right]$.

The trend-line equation is of the form:

$$
\mathrm{y}=-7.03 \ln (\mathrm{x})+127.35
$$

\section{Results of the tests with the use of FLA 002.25 magnetic fluid}

In Tab. 5 are collected results of the tests with the use of FLA 002.25 magnetic fluid. The tests were performed at the relative pressure $\mathbf{p} / \mathbf{p}_{\mathbf{k r}}=\mathbf{0 . 5}$, consequently the pressure of 0.022 $\mathrm{MPa}$ was set in the water chamber.

In Fig. 8 is presented the relation between number of seal revolutions (cycles) to the first leakage and seal rotational speed for the FLA 002.25 magnetic fluid. No test was performed at the rotational speed equal to critical one for the fluid in question.

The first measurement point depicted in the diagram concerns the test performed at the seal critical speed equal to $50\left[\mathrm{~s}^{-1}\right]$.

The trend-line equation is of the form:

$$
\mathrm{y}=-3.85 \ln (\mathrm{x})+81.07
$$

\section{COMPARISON AND DISCUSSION OF THE TEST RESULTS}

In Tab. 6 are collected the magnetic and viscosity properties of the tested fluids and values of statical critical pressures and critical speeds obtained from the tests of the seal.

Critical speed is one of the crucial parameters which characterize applicability of a magnetic fluid to operate

\begin{tabular}{|c|c|c|c|c|c|c|c|c|}
\hline $\begin{array}{c}\text { Fluid } \\
\text { amount } \\
{[\mu \mathrm{l}]}\end{array}$ & $\begin{array}{l}\text { Gap } \\
\text { height } \\
{[\mathrm{mm}]}\end{array}$ & $\begin{array}{c}\text { Critical } \\
\text { pressure } \mathbf{p}_{\mathrm{kr}} \\
{[\mathrm{MPa}]}\end{array}$ & $\begin{array}{c}\text { Relative } \\
\text { pressure } \\
\mathbf{p} / \mathbf{p}_{\mathrm{kr}}\end{array}$ & $\begin{array}{c}\text { Set } \\
\text { testing } \\
\text { pressure } \\
\mathrm{P}[\mathrm{MPa}]\end{array}$ & $\begin{array}{c}\text { Critical } \\
\text { speed } \\
{\left[\mathrm{s}^{-1}\right]} \\
\end{array}$ & $\begin{array}{c}\text { Testing } \\
\text { rotational speed } \\
{\left[\mathrm{s}^{-1}\right]} \\
\end{array}$ & $\begin{array}{c}\text { Number of } \\
\text { revolutions } \\
\text { to leakage }\end{array}$ & $\begin{array}{l}\text { Time to } \\
\text { leakage } \\
\text { [s] }\end{array}$ \\
\hline \multirow{5}{*}{100} & \multirow{5}{*}{0.1} & \multirow{5}{*}{0.0443} & \multirow{5}{*}{0.5} & \multirow{5}{*}{0.022} & \multirow{5}{*}{55} & 55 & \multicolumn{2}{|c|}{ Not measured } \\
\hline & & & & & & 50 & 2000 & 40 \\
\hline & & & & & & 45 & 9000 & 200 \\
\hline & & & & & & 40 & 384000 & 9600 \\
\hline & & & & & & 20 & 1428000 & 71400 \\
\hline
\end{tabular}

Tab. 5. Results of the tests with the use of FLA 002.25 magnetic fluid

Number of revolutions to leakage vs. motion velocity of the seal $y=-3,851 \ln (x)+81,075$ Magnetic fluid: FLA 002.25;

$\hat{\delta}=0.1 \mathrm{~mm} ; \mathrm{p}=0.022 \mathrm{MPa} ; \mathrm{p}_{\mathrm{cr}}=0.044 \mathrm{MPa} ; \mathrm{p} / \mathrm{p}_{\mathrm{cr}}=0.5$

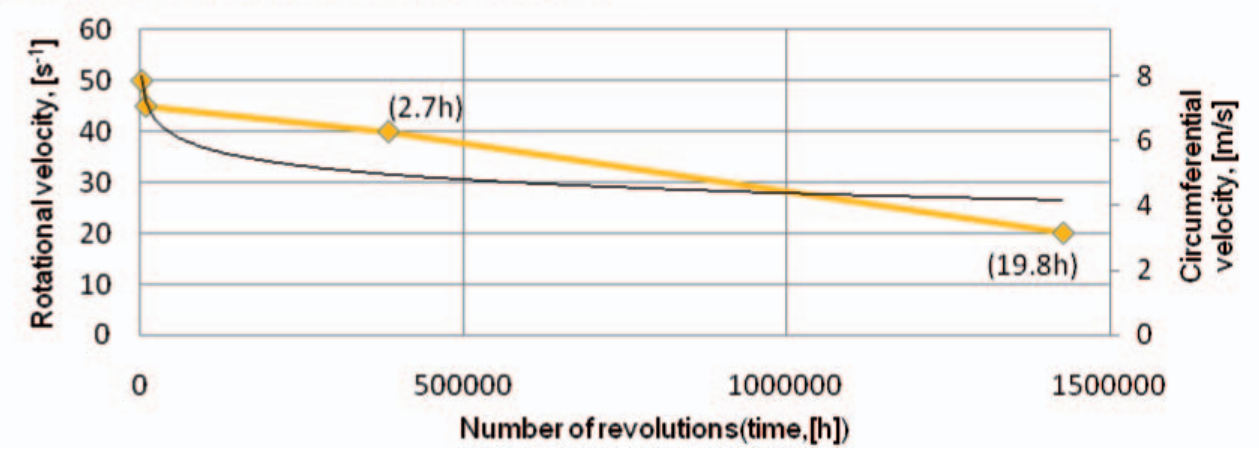

Fig. 8. Life of the seal with the applied FLA 002.25 magnetic fluid for the gap height of $0.1 \mathrm{~mm}$ and the set pressure of $0.022 \mathrm{MPa}$ 
Tab. 6. Magnetic and viscosity properties of the tested magnetic fluids, as well as values of static critical pressure and critical speed obtained from the tests

\begin{tabular}{|c|c|c|c|c|c|c|}
\hline \multirow{2}{*}{$\begin{array}{l}\text { Magnetic } \\
\text { fluid }\end{array}$} & \multirow{2}{*}{$\begin{array}{c}\text { Saturation } \\
\text { magnetization } M_{s} \\
{[\mathbf{k A} / \mathbf{m}]}\end{array}$} & \multirow{2}{*}{$\begin{array}{c}\text { Plastic viscosity at } \\
20^{\circ} \mathrm{C}, \eta_{\mathrm{pl}} \\
{[\mathrm{Pa} \cdot \mathrm{s}]}\end{array}$} & \multirow{2}{*}{$\begin{array}{l}\text { Static critical } \\
\text { pressure } p_{k r} \\
{[\mathrm{~Pa}]}\end{array}$} & \multirow{2}{*}{$\begin{array}{c}\begin{array}{c}\text { Set testing } \\
\text { pressure } \mathbf{p}\end{array} \\
{[\mathrm{MPa}]}\end{array}$} & \multicolumn{2}{|c|}{ Critical speed } \\
\hline & & & & & {$\left[\mathbf{s}^{-1}\right]$} & {$[\mathbf{m} / \mathbf{s}]$} \\
\hline FLS 040.040 & 45.00 & 0.550 & 0.0776 & 0.038 & 73 & 11.4683 \\
\hline FLS 250.020 & 25.00 & 1.120 & 0.0616 & 0.031 & 22 & 3.4562 \\
\hline FLA 003.45 & 45.00 & 0.450 & 0.0868 & 0.043 & 82 & 12.8822 \\
\hline FLA 002.25 & 25.00 & 0.725 & 0.0443 & 0.022 & 55 & 8.6405 \\
\hline
\end{tabular}

in water environment conditions. The greatest value of critical speed equal to $12.8822 \mathrm{~m} / \mathrm{s}$ was reached for FLA 003.45 magnetic fluid produced on the basis of the siloxane bearing liquid, intended for the using in acoustic devices. The smallest value of critical speed equal to $3.4562 \mathrm{~m} / \mathrm{s}$ was obtained for FLS 250.020 magnetic fluid produced on the basis of the silicon bearing liquid, intended for the using in seals.

Comparison of the obtained critical speed values show that the both FLA fluids intended for the using in acoustic devices demonstrated, during the tests, greater values of the speed than the FLS fluids to be used in seals.

It should be mentioned that the applied relative pressure $\mathbf{p} / \mathbf{p}_{\mathbf{k r}}=\mathbf{0 . 5}$ (defined as the ratio of the pressure set in the test and the static critical pressure) was kept equal in all the tests. Since the critical pressure values for particular fluids are different the tests were performed at different values of pressure in water chamber that also could influence the obtained results.

For instance, in the test with the use of FLA 002.25 fluid, conducted at the smallest value of pressure applied in the tests, much greater value of the critical speed was obtained than in the test with FLS 250.020 fluid, in spite of the much greater static critical pressure for this fluid.

In Fig. 9, are presented the life diagrams for the seals with the gap of $0.1 \mathrm{~mm}$ in height, based on the tests with the use of FLS 250.020, FLS 040.040, FLA 002.2 and FLA 003.45 magnetic fluids at the relative pressure $\mathbf{p} / \mathbf{p}_{\mathbf{k r}}=\mathbf{0 . 5}$.
Comparison of the number of seal revolutions done till loss of tightness at different motion speeds shows that within the scope of the performed tests greater life values were obtained for the seals with applied FLA 003.45 and FLA 002.25 magnetic fluids than for those with FLS 250.020 and FLS 040.040 ones.

The results, like in the case of critical speed measurements, show how important is a kind of bearing liquid for life of magnetic-fluid seal operating in water. The smallest life was obtained from the tests with the use of FLS 250.020 magnetic fluid. The result, like in the case of critical speed measurements, may be associated with the relatively high pressure set in the tests with the use of the fluid in question.

Run of the life diagrams in function of seal motion speed shows a common characteristic feature, namely: in the range of higher motion speed values the speed decreasing only slightly influences the life increasing, however in the range of lower motion speed values a relatively small decrease of the speed results in a significant increase of seal life. The feature is clearly observed in the tests with the use of FLA 003.45 and FLS 040.040 magnetic fluids characterized by higher values of saturation magnetization. For instance, in the tests with FLA 003.45 fluid, after decreasing the seal rotational speed value from $82 \mathrm{~s}^{-1}$ to $40 \mathrm{~s}^{-1}$, i.e. by $50 \%$, the number of revolutions to leakage increased by $8,151 \times 10^{4}$ cycles, and the subsequent decreasing the seal rotational speed value from $40 \mathrm{~s}^{-1}$ to $30 \mathrm{~s}^{-1}$, i.e. by $10 \%$, resulted in the life increase by $1.718 \times 10^{6}$ cycles only.

\section{Number of revolutions to leakage vs. motion velocity of seals Magnetic fluids: FLS 040.040; FLS 250.020; FLA 003.45; FLA 002.25 $\delta=0.1 \mathrm{~mm} ; \mathrm{p} / \mathrm{p}_{\mathrm{cr}}=0.5$}

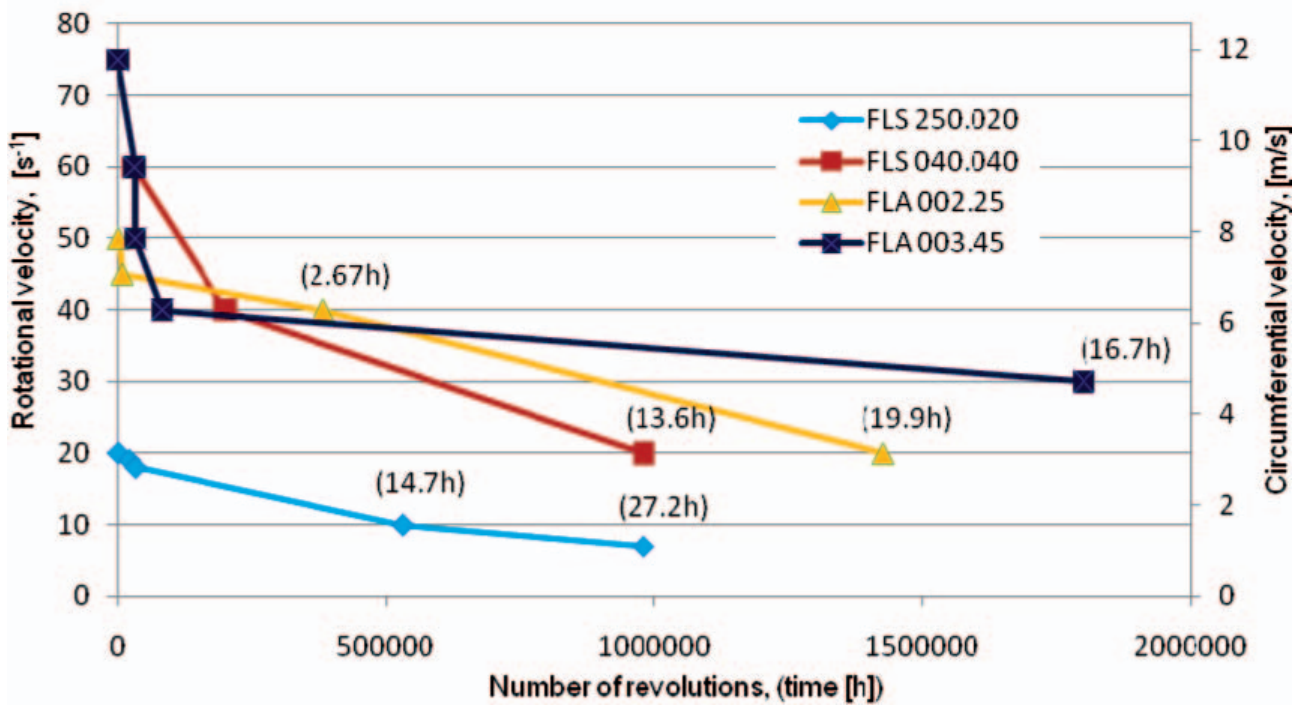

Fig. 9. Comparison of the seal life values for various magnetic fluids used in the tests at the relative pressure of 0.5 and the gap height of $0.1 m m$ 


\section{SUMMARY AND CONCLUSIONS}

The performed tests of the single-stage magnetic-fluid seals operating in water environment confirmed correctness of the assumptions and procedure of the tests realized by means of the MAST L1-V2 test stand.

On the basis of the obtained results and observations, despite the limited range of the applied geometric and operational parameters, the following final conclusions and recommendations can be suggested:

1. The magnetic fluids made with the use of silicon liquids as a carrier liquid may be effectively applied to seals intended to operate in water, but in a limited range of seal motion speeds.

2. The tests in question should be supplemented by similar tests in sea water conditions aimed at checking chemical resistance of the magnetic fluids.

3. Life of magnetic-fluid seals operating in water greatly depends on seal motion speed. In the small motion velocities range the considerable growth of the lifetime with decrease of the motion velocity is observed. In the range of greater motion velocities the seal lifetime is very low.

4. The tests demonstrated that the pressure applied to magnetic -fluid seal, despite relatively low ratio of operational pressure/critical pressure was of significant effect on the obtained results. An additional research on influence of the pressure on life of magnetic-fluid seal operating in sea water of different salinity should be performed.

5. The MAST L1-V2 test stand for the testing of magneticfluid seals ensures correct run of the test. However its construction should be improved as to the detection of leakage because in its present state to precisely determine the instant of leakage is difficult.

\section{BIBLIOGRAPHY}

1. Szydło, Z., Zachara, B., Ochoński, W.: Ferro-magnetic fluids and their application in machine building (in Polish). $1^{\text {st }}$ Conference on automation of machines, devices and processes, Krynica, 1999

2. Rosensweig, R.E.: Ferrohydrodynamics. Dover Publications, Inc. Mineola, New York, 1997

3. Rinaldi, C., Chaves,A, Elborai, S.,He, X., Zahn, M.: Magnetic fluid rheology and flows. Current Opinion in Colloid \& Interface Science Vol.10, Issue $3 \div 4$, October, 2005

4. Orlov, D. B., at al..: Eksperimentalnoe issledovanie resursa magnitozidkostnych uplotnenij pri germetazicii zidkich sred (in Russian). Magnitnaya Gidrodinamika, No 4, 1989.
5. Kurfess,J., Muller, H.K.: Sealing liquids with magnetic fluids. Journal of Magnetism and Magnetic Materials,85,(1990)

6. Vihersalo, J., at al.: Sealing of Liquids with Magnetic Fluid Seals. Proc. of $6^{\text {th }}$ Nordic Symposium on Tribology, NORDTRIB'94, Uppsala, Sweden, 12 $\div 15$ June 1994.

7. Chorney, Alvan F.; Mraz, Will.: Hermetic Sealing with Magnetic Fluids. Machine Design; ProQuest Science Journals May 64, 9, 7, 1992

8. Mitamura, Y., Arioka, S., Sakota, K., Azegami, M.: Application of a magnetic fluid seal to rotary blood pumps. J. Phys.: Condens. Matter 20 (2008) 204145

9. Szydło Z., Ochoński W., Zachara B. (inventors): Measurement head for the testing of parameters of ferro-magnetic fluid seals (in Polish). Stanisław Staszic Mining and Metallurgy Academy (AGH), Cracow, Patent application specification No. PL 377598 A1, dated 2005-10-12; published on 2007-04-16. Bulletin of Polish State Patent Office No. 8, 2007

10.Szydło, Z., Matuszewski, L.: Ring thruster - a preliminary optimisation study of ferro-fluid seal and propeller. Polish Maritime Research, Special issue No. S1, 2007

11.Szydło, Z., Matuszewski, L.: The application of magnetic fluids in sealing nodes designed for operation in difficult conditions and in machines used in sea environment. Polish Maritime Research, No. 3, Vol. 15, 2008

12.Szydło, Z.: Tests of a seal with applied magnetic fluids (water - air) - preliminary determination of its life and permissible linear speed (in Polish). Research project No. 6.6.130.261, AGH, 2008, (unpublished)

13.Bonvouloir, J.: Experimental Study of High Speed Sealing Capability of Single stage Ferro fluidic Seal. ASME Transactions, Journal of Tribology, Vol.119, July, 1997

14.Ferrolabs, Inc., Sterling, VA, United States: http://www. ferrolabs.com/ 2010

15."ENES”, Zientek P., Warsaw: www.magnesy.pl/ 2010

\section{CONTACT WITH THE AUTHORS}

Leszek Matuszewski, Ph. D.

Faculty of Ocean Engineering and Ship Technology

Gdansk University of Technology Narutowicza 11/12

80-233 Gdansk, POLAND

e-mail: leszekma@pg.gda.pl

Zbigniew Szydło, Ph.D.

AGH University of Science and Technology Faculty of Mechanical Engineering and Robotics Al. Mickiewicza 30 31-069 Kraków, POLAND e-mail: zbszydlo@agh.edu.pl 